\title{
ADAPTATIONS OF DESIGN PROJECT MANAGEMENT EDUCATION IN THE PANDEMIC
}

\author{
Maurício BERNARDES, Sandro FETTER and Geísa OLIVEIRA \\ Federal University of Rio Grande do Sul
}

\begin{abstract}
The efficiency of project management processes is strongly related to the way in which the manager and team build, organize, plan, and control the project. Project management processes become even more important when, in one-of-a-kind projects, there are no reports or historical data available on the application of certain work procedures by the company. In this regard, frequent testing and learning of new routines emerge as essential elements to be considered for planning and control of a project.

This paper explores the experience of adapting projects of an undergraduate program in design, whose classes were taught using only a remote learning approach during the pandemic. The data analysed in the study refer to observations on the students' modus operandi recorded in field notes by the authors of this paper, who oversaw the course; the students' answers to an interview on the use of tools and practices in project management during the pandemic; analysis of discipline management documents, i.e., a detailed and controlled project timeline and weekly task assignment plan.

The study showed that student performance did not differ between the remote and the on-site modes. The biggest challenges were found in the prototyping and game testing stages. However, these challenges were partly minimized by utilizing online collaborative work platforms, adopted exclusively for such activities.
\end{abstract}

Keywords: Project management, design, pandemic, adaptations

\section{INTRODUCTION}

The existence of reliable historical data that can be used to support design of management processes in new projects contributed to attaining delivery and cost goals. Nevertheless, the experience and routine of team members involved in new projects often impact results [3]. This occurs more significantly in situations in which the people involved in the project possess little knowledge of management processes [4] [5] or, in addition, in contexts of greater uncertainty.

This article describes the experience of its authors regarding adaptation, during the pandemic, of process management areas for students of a design course, with emphasis on product and graphic design. The data analysed in the study refers to observations on the students' modus operandi recorded in field notes by the authors of this paper, the students' answers to an interview on the use of tools and practices in project management during the pandemic, and analysis of discipline management documents, i.e., a detailed and controlled project timeline and weekly task assignment plans.

The study showed that the course chosen for the Emergency Remote Teaching (E.R.T.) mode was able to maintain the same performance standard of classes taught completely on-site. For the Emergency Remote Teaching mode, we utilized the definition of [7], which refers to the context of teaching the classes with asynchronous and synchronous content, without on-site meetings.

\section{CONTEXT OF PROJECT MANAGEMENT DESIGN COURSE}

In the study course, the classes are geared towards project development, according to the learning by doing approach [8]. To this end, the course was gamified. In this proposal, the professors personify the role of CEOs of a design company and inform the students that they are their employees. Next, they divide the group into teams consisting of students specialized in product design and graphic design. Shortly afterwards, they inform them that a large game development company has contracted a new project and the teams have been tasked with developing a board game that can be played within an hour, including reading the instructions. The teams should deliver a high-fidelity prototype of the game at the 
end of the semester. While the board games are developed, the professors teach the students how to manage their projects.

In the in on-site context, the classes take place with the support of the Moodle platform, on which the essential course documents are made available: lesson plans, standards of deliverables of management and board game documents; bibliography; project management file archives from previous semesters; professors' feedback on presentations, documents delivered by students and conceptual spreadsheets. At the end of the semester, the students' high-fidelity prototypes are tested by other students and professors.

Owing to restrictions imposed by the pandemic, the professors had to adjust the course to the Emergency Remote Teaching (E.R.T) mode, as advised by the university's lawyers. This adaptation was based on previously recorded theoretical content, taught in asynchronous form, made available on Moodle links, and on synchronous online classes, utilizing the flipped classroom approach [9]. Furthermore, the strategy was implemented to adapt the students' learning process to their new work routines. Microsoft Teams, made available by the university, was used to teach, and record the synchronous classes. Moodle continued to be used as a central element in the course, but with an extra amount of information in comparison to the completely on-site context. This information consisted of hyperlinks to the asynchronous theoretical classes and the 'dear diary' area, whose purpose is to register the progress of the asynchronous classes. The goal of the 'dear diary' area is to resume quick entries that might be a source of reference for professors and students throughout the class.

In this context, new challenges were posed by the physical prototypes since the students should be able to handle the pieces of the project [10]. Furthermore, the members of the teams need to be in regular contact with each other and observe ways to streamline the mechanic, the dynamic, and the aesthetic components of the game [11].

\section{RESEARCH METHOD}

This research is qualitative descriptive, based on the collection of several data sources. The data are relative to the 2019-2 semesters (on-site classes) and 2020-1 (remote classes). Table 1 shows the total number of students per semester.

Table 1. Number of students per semester

\begin{tabular}{|c|c|c|}
\hline Semester & Mode & Students \\
\hline $2019-2$ & On-site & 26 \\
\hline $2020-1$ & Remote & 29 \\
\hline
\end{tabular}

The documentary data were extracted from previous assignments delivered by students and audited by the professors. Auditing took place to guarantee that the analysis indicators were correctly collected, and calculation procedures were double checked to reduce the error rate. The following data were analysed:

- $\quad$ Student progress: final class grades, project management grades and design team member grades. Notably, the manager and team member are assigned grades by the students in the class at the end of the semester.

- Percent Plan Complete (PPC): this indicator is related to the efficiency of the short-term plan utilized by students in the course and follows the theoretical basis of the Last Planner System [12]. The PPC average was calculated based on the data collected by all the weekly plans used by the students.

- PPC variation coefficient: this indicator was used to check for possible differences in PPC variability between on-site and remotely taught semesters. Variability analysis is important, as it is a consequence of interruptions in the workflow [13]. Thus, differences in the variation coefficient can indicate the existence of further workflow interruptions from one semester to another.

- Average weekly hours per work group: aimed to measure the team effort throughout the project, with the intent of checking for possible differences between on-site and remotely taught semesters. Hours were logged by the students, over the course of the two academic semesters, on the MS Excel spreadsheets made available by the professors.

- $\quad$ Problems that caused the lack of completion of weekly work goals: for this variable, the problems collected in the master's dissertation of [14] were used and were based on course data from on-site 
semesters. The data from 2020-1 was identified in the weekly teamwork plans and recorded by the authors of this study.

- Data originating from interviews with remotely taught semester students: the purpose was to detect the major difficulties faced by remotely taught students, as well as enable them to make suggestions for improvements in future semesters.

\section{PROBlems faced in the AdAPtATION OF the COURSE}

Prototyping and testing of the game were the major difficulties faced by the students in the remotely taught semester, owing to the lack of on-site work meetings. Because on-site meetings could not be held, the physical board game development project became more challenging, although not unfeasible.

Although on-site meetings could not take place for game testing purposes, some teams attempted to resolve the problem by making low-fidelity physical prototypes available to all team members. Despite the limitations, the initial tests took place via remote meetings. Some students, who lived with their parents, asked them to participate in the play tests.

Since it was difficult to carry out on-site playability testing, one student noted that their team used the Miro ${ }^{\circledR}$ platform to simulate the execution of the card game being developed (Figure 1). In this case, one of the team members knew all the players' cards so that he or she could distribute them from a stack of cards that had been placed face-down. This student also undertook the role of an observer, while the other players tested the manual and the other pieces of the game. The observing student did not participate in the play test.

The alternative presented to test the prototype, although only virtually, is one of the possibilities of implementing course adaptations. This is corroborated by [15], p. 39: 'If the lack of prototyping resources prevents completion and delivery of the final prototype, we may need to be flexible and modify the scope of individual projects and course deliverables (such as the final prototype) to accept what teams are able to deliver at the end of the semester with the alternate resources to which they may have access.'

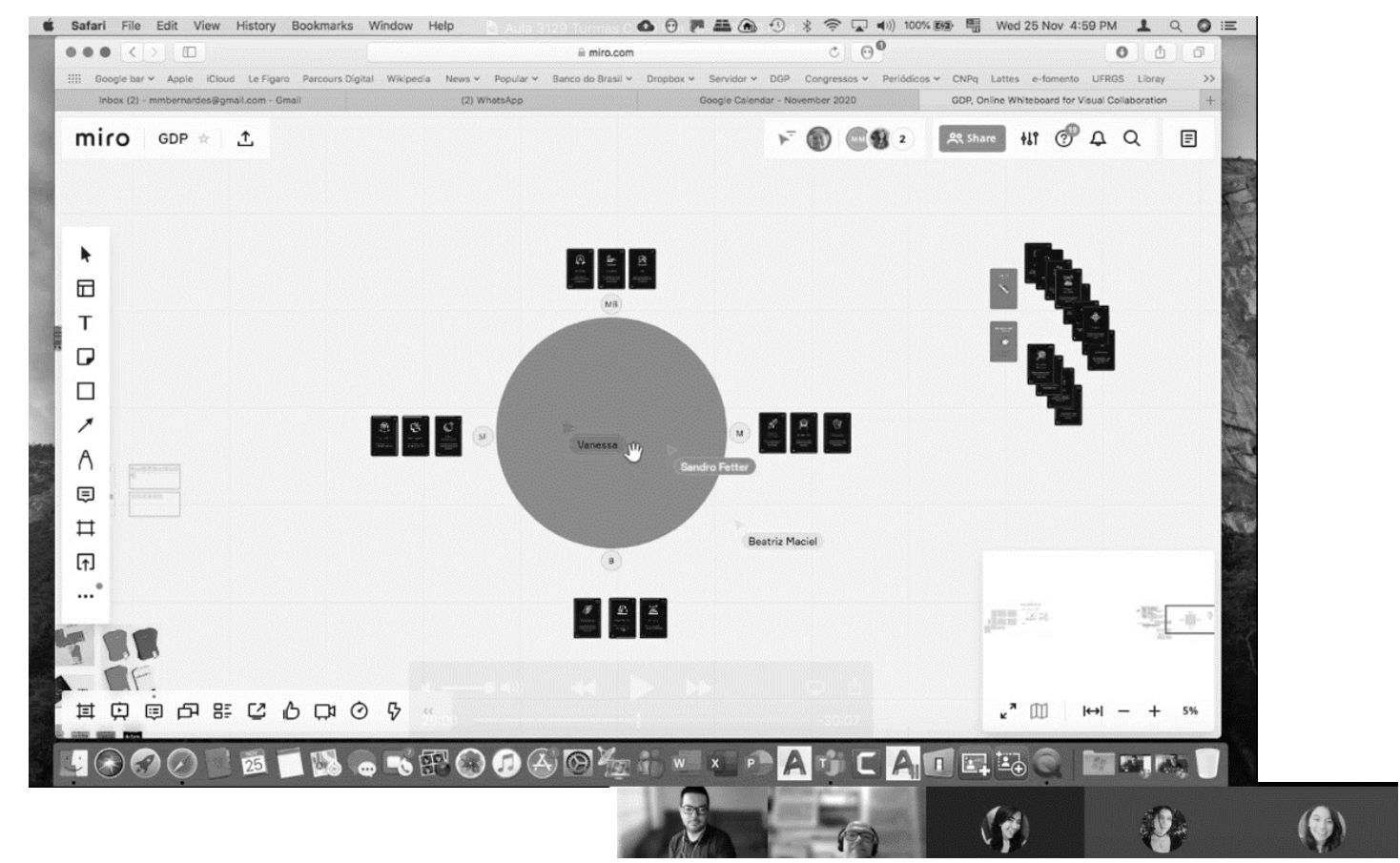

Figure 1. Remote card game testing

Table 2 shows a perceptual comparison amongst the most frequent problems recorded by the students in their weekly work plans. The problems in the Table are listed in decreasing order to facilitate comparisons with the remotely taught semester. 
Table 2. Problems detected in on-site and remotely taught environments.

\begin{tabular}{|c|c|c|}
\hline Problem & On-site & Remote \\
\hline Difficulties in estimating task duration & $32.31 \%$ & $13.79 \%$ \\
\hline Unexpected personal events & $23.08 \%$ & $44.83 \%$ \\
\hline Overload of projects developed in tandem & $10.77 \%$ & $27.59 \%$ \\
\hline Communication noise & $10.77 \%$ & $3.45 \%$ \\
\hline Lack of technical knowledge of software or materials & $10.77 \%$ & $6.90 \%$ \\
\hline Inertia in decision-making & $6.15 \%$ & $3.45 \%$ \\
\hline Lack of commitment amongst team members & $3.08 \%$ & $0.00 \%$ \\
\hline Neglected phases & $3.08 \%$ & $0.00 \%$ \\
\hline
\end{tabular}

In the context of the course, as shown in Table 2, the biggest challenge in the on-site mode was to estimate design task duration. However, in the remotely taught semester, the occurrence of unexpected personal events stood out. An in-depth analysis should be made of these data. At first, one can presume that in the switch from on-site to remote learning, in the case of adopting new routines, the project is more impacted by unexpected personal events than by management issues. In this manner, to deal with unexpected personal events, the data from this research prompts the search and use of technological resources that are adjustable to the teaching and learning modes of the students within this new context. It is also worth noting that, for the present study, regardless of either the on-site or remotely taught modes, there is always a lack of commitment of one or more members of the teams during project completion. This was detected during the interviews. Importantly, the lack of commitment is a type of problem that should be recorded when there is no other reason to justify the late delivery itself. This is also corroborated by the answers to anonymous evaluations of the managers and designers, completed by the students at the end of the course. However, the students are reluctant to formally report this issue to their professors because they wish to avoid conflict amongst their peers. This explains the lack of documentation around this issue at the end of the course. For this reason, it can be concluded that this issue should be clarified and worked through at the beginning of the course, with the intent of improving the ability of students to deal with conflict resolution in the real world, whether using the on-site or the remotely taught approach. If the student experienced unexpected personal events, such as health problems, they should submit a doctor's note to justify their absence. Nevertheless, transparent work should be the goal. If a student does not have the ability to keep up with the workload, it is recommended that they negotiate with the project manager to reduce the workload over a couple of weeks. However, they should inform the project manager when they will increase their workload for compensation. This practice is discussed in the theorical classes of the project management course throughout the semester, but it is hardly put into practice by the students in both on-site and remotely taught modes.

For student performance data analysis, Table 3 shows the comparative results between the averages of both modes (on-site and remotely taught), assuming equivalent variations. Student grades vary on a scale of 0 to 10 . No significant differences were found amongst the averages. This is an indicator that student performance was not affected by the change in teaching approach (on-site versus remotely taught).

According to one of the students participating in the remotely taught mode, there were advantages to studying remotely. One of them is the possibility of watching the theoretical class beforehand, which helped the team members to do their assignments.

Considering the lack of significant differences in team member performance between the on-site and remotely taught semesters, certain data from Table 3 need to be deeply discussed by way of comparison of the adopted teaching modes. It can be noted that the standard deviation of the average weekly hours worked in the remotely taught semester was higher than that of the on-site semester. In the remotely taught semester, there was a variation of 17.55 to 39.95 hours of weekly work between teams. In the onsite semester, this variation ranged between 27.2 and 37.57 hours. 
Table 3. T-test (95\% confidence interval of the difference)

\begin{tabular}{ccccc}
\hline Analysed variable & $2019-1$ & $2020-1$ & $\mathrm{t}$ & $\mathrm{p}$ (two-tailed) \\
\hline Designer's average grade & 8.70 & 9.28 & 2.0048 & 0.1371 \\
Standard deviation & 1.5109 & 1.4105 & & \\
\hline Manager's average grade & 8.92 & 9.36 & 2.0048 & 0.1865 \\
Standard deviation & 1.0903 & 1.3571 & & \\
\hline Student's final grade & 8.94 & 9.31 & 2.0180 & 0.1149 \\
Standard deviation & 0.5528 & 1.0794 & & \\
\hline Average weekly hours & 32.38 & 28.55 & 2.4469 & 0.5639 \\
Standard deviation & 5.1869 & 11.4018 & & \\
\hline Average PPC & $89.7 \%$ & $92.6 \%$ & 2.4469 & 0.6153 \\
Standard deviation & $9.8 \%$ & $4.4 \%$ & & \\
\hline PPC variation coefficient & $14.93 \%$ & $11.92 \%$ & 2.4469 & 0.5048 \\
Standard deviation & $7.12 \%$ & $4.61 \%$ & & \\
\hline
\end{tabular}

Upon analysing the data on hours worked together with the problems faced by the students in both semesters (Table 2), it can be assumed that, during the adaptation, the effort made by some teams might have been affected by unexpected personal events. The analysis of the evidence extracted by monitoring the assignments and the interviews with students, showed that the unexpected events did impact students' efforts. The parents of one of the team members contracted Covid- 19. The student had to help his siblings take care of his parents. This situation impacted the delivery of group assignments, even though the team decided to reduce the scope and complexity of their ongoing project. It is worth noting that the course professors offered special assistance to the team to help them reach their goals. However, the students on the team had not asked for this type of assistance.

\section{FINAL CONSIDERATIONS}

Even without significant differences between student performance across on-site and remotely taught semesters, the findings of this study offer insights for the development of research oriented towards new forms of virtual prototyping and online game board testing. It can be affirmed that these were the most conflict points in carrying out the course via remote learning. Therefore, it can be assumed that, while there is a lack of technological tools that can simulate a testing environment similar to that of on-site modes, the reduction in complexity of the product being developed becomes essential for the application of the learning by doing approach within the context of remote learning. In the project management for the design course, the Covid-19 pandemic posed novel challenges and the professors could observe and analyse how the students can, in fact, apply skills to overcome obstacles regarding the lack of on-site contact amongst team members as the project develops.

Importantly, it is noteworthy that the study shows us the need to help students develop skills to deal with unexpected personal events in a more practical and meaningful manner. They should know what to do to correct deviations resulting from these events because they are usually beyond one's control. During their education, design students should practice the process of analysis and decision regarding these types of events, so that they can be better prepared for real situations in the job market. Notably, during the pandemic, the relative frequency of these problems has doubled. Although these events occur both in the face-to-face and in the remote modes, the increased frequency of the problem in the remote mode indicates that a risk response plan - more particularly focused on these types of problems - needs to be detailed and developed with the students since the beginning of the semester. This way, the implementation of a strategy to prepare students to make decisions in uncertain situations, becomes even more challenging, because some of these events are sometimes related to one's emotional state. Thus, developing and addressing the human factor in the course is essential for adapting education for management of design projects in times of pandemic. In these terms, a teaching approach that privileges only the results of numerical indicators and the final quality of the project, without considering people's difficulties, desires, and needs, can impact the education of design students in the management area. This poses an important challenge, in future academic semesters, for the course discussed in this article. 
Other issues occurring in the remotely taught mode took place in the on-site mode as well. This indicates professors need to provide students with appropriate instruction to better prepare them for the real world. It is worth noting that the purpose of universities, especially as regards design courses, is to offer the most productive teaching methods [16]. If we search for design solutions to the problems that affect us, we can explore new educational opportunities that allow us to perform well in adverse situations.

\section{REFERENCES}

[1] Song L. and AbouRizk S. M. Quantifying Engineering Project Scope for Productivity Modelling. Journal of Construction Engineering and Management, 2005, 131(3), 360-367.

[2] Peixoto C., Audy J., and Prikladnicki R. The importance of the use of an estimation process. In Proceedings of the 2010 ICSE Workshop on Software Development Governance, May 2010, pp. 13-17, https://doi.org/10.1145/1808981.1808983.

[3] Bredillet C., Tywoniak S. and Tootoonchy M. Exploring the dynamics of project management office and portfolio management co-evolution: A routine lens. International Journal of Project Management, 2018, 36(1), 27-42.

[4] Engelbrecht J., Johnston K., and Hooper V. The influence of business managers' IT competence on IT project success. International Journal of Project Management, 2017, 35(6), 994-1005.

[5] Hyväri I. Success of projects in different organizational conditions. Project Management Journal, 2006, 37(4), 31-4.

[6] Gomes L., Salerno M., Phaal R., and Probert D. How entrepreneurs manage collective uncertainties in innovation ecosystems. Technological Forecasting \& Social Change, 2018, 128, 164-185.

[7] Hodges, C., Moore S., Lockee B., Trust T., and Bond A. The Difference Between Emergency Remote Teaching and Online Learning. EDUCAUSE. Available: https://er.educause.edu/articles/2020/3/ the-difference-between-emergency-remote-teaching-andonline-learning/ [Accessed on 2021, 3 February], (2020) 27 March.

[8] Hedrick J. Learning by doing. NACTA Journal, 2011, 55(3), 98-99.

[9] Awidi I. and Paynter M. The impact of a flipped classroom approach on student learning experience. Computers \& Education, 2019, 128, 269-283.

[10] Sperhacke S. and Bernardes M. Designing tabletop games with the use of prototypes. In: Prototyping across the Disciplines: Designing Better Futures. Chicago: Intellect, 2020, 1, $102-$ 120 (Organized by Jennifer Roberts-Smith; Stan Ruecker; Milena Radzikowska).

[11] Hunicke R., LeBlanc M., and Zubek R. A Formal Approach to Game Design and Game Research. Research Gate. Available: https://www.researchgate.net/publication/228884866_MDA_A_Formal_Approach_to_Game_De sign_and_Game_Research [Accessed on 2021, 30 January], (2021) 30 January.

[12] Ballard G. Managing workflow on design projects: a case study. Engineering, Construction and Architectural Management, 2002, 9(3), 284-291.

[13] Ballard G. and Howell G. Shielding production: Essential step in production control. Journal of Construction Engineering \& Management, 1998, 124(1), 11-17.

[14] Silva J. Guidelines for avoiding and correcting delays in the development of tabletop game projects. Porto Alegre: Postgraduation Program in Design, Federal University of Rio Grande do Sul, 2020. (Master Thesis). (In Portuguese).

[15] Goldberg J. Finding Alternate Resources for Completing Senior Design Projects During the Current COVID-19. IEEE pulse, 2020, 11(3), 38-40.

[16] Coates H., Xie Z. and Hong X. Engaging transformed fundamentals to design global hybrid higher education. Studies in Higher Education, 2021, 46(1), 166-176. 